\title{
Ameliorative effect of Nigella Sativa on Absolute Weight, Relative Weight, and Body Weight after Doxorubicin Induced Kidney of Albino Rats \\ Wazir Ahmed, ${ }^{1}$ Sadia Sundus, ${ }^{2}$ Maria Mohiuddin, ${ }^{3}$ Sarwath Fatimee, ${ }^{4}$ Ashoke Kumar, ${ }^{5}$ Abdullah Jan ${ }^{6}$
}

\begin{abstract}
Background: Doxorubicin (DOX) belongs to anthracyclines antibiotics, used for the treatment of several malignancies, and its use is limited because of various organ injuries. The seeds of Nigella sativa are beneficial in several illnesses.

Objective: To explore the ameliorative role of Nigella sativa on body weight, absolute and relative weight of on Doxorubicin-induced albino rats kidney.

Methodology: Study design: Comparative study. Setting: BMSI (Anatomy Department), JPMC, Karachi. Study duration: $26^{\text {th }}$ January to $2^{\text {nd }}$ March 2017. Forty adult albino rats, 90-120 days old, weighing between 180 200 grams, were taken from the animal house and distributed into four groups. Group-A1 was the control group, Group-B1 was given Doxorubicin, 3mg/kg bw/week, intraperitoneally (ip), Group-C1 treated with Doxorubicin (3mg/kg bw/week intraperitoneally) and NS (1000mg/kg bw/week orally) daily, and Group-D1 were given only NS (1000 $\mathrm{mg} / \mathrm{kg}$ bw orally).

Results: The body weight of Group A1 was considerably elevated ( $\mathrm{p}=0.001)$ when compared with Group B1 and $\mathrm{C} 1$. The body weight was considerably decreased $(\mathrm{p}=0.001)$ in Group B1 comparison with Group A1, C1, and D1 but a highly significant raise $(\mathrm{p}=0.001)$ in the absolute and relative weight of the kidneys was observed in Group B1as compared to $\mathrm{A} 1, \mathrm{C} 1$, and D1.

Conclusion: This study concludes that Nigella sativa restored the body weight, absolute and relative kidney weight in Doxorubicin treated group.

Keywords: Doxorubicin, Nigella sativa, Intraperitoneal, Thymoquinone

Article Citation: Ahmed W, Sundus S, Mohiuddin M, Fatimee S, Kumar A, Jan A. Ameliorative effect of Nigella Sativa on Absolute Weight, Relative Weight, and Body Weight after Doxorubicin Induced Kidney of Albino Rats. JSZMC 2021;12(4):21-25. DOI: https://doi.org/10.47883/jszmc.v11i04.203
\end{abstract}

This Open Access Article in Journal of Sheikh Zayed Medical College is licensed under a Creative Commons Attribution- 4.0 International License(CC BY 4.0).

\section{Introduction}

Anticancer drug Doxorubicin (DOX) belongs to anthracyclines antibiotics. It is necessary for the treatment of several malignancies like Hodgkin's disease, non-Hodgkin's lymphomas, hematological well as solid tumors. ${ }^{1}$ Its clinical use is limited because various organ injuries are related to DOX. It is related to intercalation into DNA which prevents the proliferation of rapidly growing cancer cells and inhibition of irondependent oxidative damage of biological macromolecular synthesis. ${ }^{2}$ DOX leads to disturbance in oxidant-antioxidant systems such as membrane lipid peroxidation which causes tissue injuries. ${ }^{3}$ The injurious effect of DOX is mediated through the free radical formation. It's absolutely not targeted to the tumors but the growth of various other body cells are also effected $^{4,5}$ like raised permeability of glomerular capillaries and glomerular atrophy.

The seeds of Nigella sativa are beneficial in several illnesses and are also used as a food preservative as well as spices. ${ }^{7}$ It cultivates in several countries such as Pakistan, Afghanistan India, Indonesia, and Italy. The flowers are blue and white in color, while the fruit is huge and consists of 3-7 united follicles. Currently various clinical and animal studies have revealed that its extracts are used as antidiabetic, antibacterial, antilithiatic, antioxidative, antihistaminic, immunomodulatory, hypotensive, bronchodilatory, nephroprotective, hepatoprotective, gastroprotective and neuroprotective agent. ${ }^{10}$ Thymoquinone is one of the constituents of Nigella sativa oil acts as an antioxidant and protects renal cells against toxic effects. ${ }^{11}$ This is the reason we planned this study to assess the nephroprotective role of Nigella sativa on doxorubicin-induced kidney injuries.

1. Department of Anatomy, Makran Medical College, Makran, Pakistan.

2. Department of Anatomy, Iqra Medical and Dental Medical College, Karachi, Pakistan.

3. Department of Anatomy, Hamdard Medical University, Karachi, Pakistan.

4. Department of Anatomy, Fatima Jinah Dental College, Karachi, Pakistan.

5. Department of Anatomy, Shaheed Mohtarma Benazir Bhutto Medical University, Pakistan.

6. Department of Pharmacology, Loralai Medical College, Balochistan, Pakitan.

Correspondence: Dr. Wazir Ahmed, Assistant Professor, Department of Anatomy, Iqra Medical \& Dental College, Karachi, Pakistan. 


\section{Methodology}

This was a five weeks comparative study was conducted in the Department of Anatomy, BMSI, JPMC, Karachi after getting ethical approval from the Ethical Committee of the Institute. 90-120 days old forty Albino rats, weighing 180-200gm were got from the Laboratories of Brooklyn, USA and kept in the animal house of JPMC, Karachi. Study duration: $26^{\text {th }}$ January to $2^{\text {nd }}$ March 2017. Rats were separated into A1, B1, C1, and D1 Groups. Each group was labeled and kept in a separate cage. Before the experiment, each animal was weighed. Control Group-A1 was given normal laboratory diets. Group B1 was given injectable Doxorubicin intraperitoneally $3 \mathrm{mg} / \mathrm{kg}$ per week. Group C1 were given injectable Doxorubicin intraperitoneally (ip) $3 \mathrm{mg} / \mathrm{kg} /$ body weight per week along with aqueous Nigella Sativa $1000 \mathrm{mg} / \mathrm{kg}$ by mouth every day. Group D1 was only given aqueous Nigella Sativa $1000 \mathrm{mg} / \mathrm{kg}$ body weight by mouth every day. The weight of the animals was noted before and after the experiment.

At the completion of the study, animals were sedated with ether and the kidneys were removed by midline incision in the abdomen. After drying with filter paper, they were weighed on the Sartorius balance. After recording the mean weight of the kidneys, the kidney weight/body weight percentage was calculated according to the formula, organ weight ratio $(\%)=$ organ weight $\mathrm{X}$ 100/body weight. The absolute weights of kidneys were recorded in each group with Sartorius electronic balance and their relative weight was calculated:

The relative weight of group

$=$ Mean Weight of Kidneys $(\mathrm{G}) \quad$ X 100

Final Weight of Animals

Preparation of Nigella Sativa: After drying the seeds of Nigella Sativa, we crushed them and the extract powder was kept in the refrigerator.

Doxorubicin: Adriblastina vials (Pfizer Pharma), which contains Doxorubicin hydrochloride in the form of freeze-dried powder $50 \mathrm{mg} / 25 \mathrm{ml}$ dissolved in saline solution was used as an injectable and intraperitoneally injected at the doses of $3 \mathrm{mg} / \mathrm{kg} /$ week.

\section{Results}

Animals were observed for their general appearance, behavior, and mortality during the study. Group-A1 remained healthy, active, and responded quickly to the external stimuli throughout the study. They had normal food intake and weight gain was within normal limits. Group-B1: Animals looked ill and weak, lethargic and their response to stimuli was sluggish at the end of the study. They had decreased appetite and a noticeable loss of their body weight.

At the site of injection, a red-colored laceration was observed. Group-C1: Animals appeared to be healthy, and responded well to the stimuli. They had an unnoticeable loss of their appetite and body weight but red exudates accumulation was observed around the eyes. Group-D1: Animals remained healthy, active, and responded quickly to the external stimuli. Their appetite and food intake were good with normal weight gain. All the rats were alive throughout the period of the study.

\section{Body Weight}

Group A1: Mean value of (IBW) and (FBW) in group-A was $203.70 \pm 17.89,221.80 \pm 20.12 \mathrm{gm}$ respectively. There was a significant increase $(\mathrm{p}=0.048)(\mathrm{FBW})$ when compared (IBW) (Table-I).

Group-B1: The mean value of (IBW) and (FBW) in group-B1 was $207.50 \pm 19.30,152.90 \pm 14.67 \mathrm{gm}$ respectively. A highly significant reduction in weight was observed $(p=0.001)(F B W)$ in comparison with its (IBW) as compared to group-A1 (Table-I)

Group-C1: The mean value of (IBW) in group-C1 was $219.00 \pm 22.17,202.60 \pm 22.32 \mathrm{gm}$ respectively. There was an insignificant decrease $(p=0.117)$ (FBW) in group-C1 when compared with its (IBW). There was an insignificant decrease $(p=0.835)$ (FBW) in group-C1 in comparison with Group A1 and there was a significant rise $(\mathrm{p}=0.001)(\mathrm{FBW})$ in group-C1 in comparison with Group B1 (Table-I).

Group-D1: The mean value of (IBW) and (FBW) in group-D1 was $204.20 \pm 17.05,219.20 \pm 19.76 \mathrm{gm}$ respectively.

The (FBW) of Group D1 was significantly increased $(p=0.086)(F B W)$ as compared with its (IBW). An insignificant increase was observed $(p=0.901)$ (FBW) in Group D1as compared to Group A1. The (FBW) of Group D1 was considerably raised $(p=0.001)$ when compared with Group B1. There was an insignificant rise $(\mathrm{p}=0.922)(\mathrm{FBW})$ in Group D1 as compared to Group C1 (Table-I). 
Table-I: Comparison of mean initial and mean final Body Weights (gm) in various groups of Albino Rat $(n=40)$

\begin{tabular}{|c|l|c|c|c|}
\hline \multirow{2}{*}{ Groups } & \multirow{2}{*}{$\begin{array}{l}\text { Intervention } \\
\text { Given }\end{array}$} & \multicolumn{3}{|c|}{ Mean Body Weights } \\
\cline { 2 - 5 } A1 $(\mathrm{n}=10)$ & Control & $203.70 \pm 17.89$ & $221.80 \pm 20.12$ & 0.048 \\
\hline B1 $(\mathrm{n}=10)$ & Doxorubicin & $207.50 \pm 19.30$ & $152.90 \pm 14.67$ & 0.001 \\
\hline C1 $(\mathrm{n}=10)$ & $\begin{array}{l}\text { Doxorubicin } \\
\text { and Nigella } \\
\text { sativa }\end{array}$ & $219.00 \pm 22.17$ & $202.60 \pm 22.32$ & 0.117 \\
\hline D1 $(\mathrm{n}=10)$ & $\begin{array}{l}\text { Nigella } \\
\text { sativa }\end{array}$ & $204.20 \pm 17.05$ & $219.20 \pm 19.76$ & 0.086 \\
\hline $\begin{array}{l}\text { Numerical } \\
\text { Evaluation }\end{array}$ & \multicolumn{3}{|c|}{ P-value } \\
\hline B1 vs A1 & \multicolumn{3}{|c|}{0.001} \\
\hline C1 vs A1 & \multicolumn{3}{|c|}{0.835} \\
\hline D1 vs A1 & \multicolumn{3}{|c|}{0.001} \\
\hline B1 vs C1 & \multicolumn{3}{|c|}{0.922} \\
\hline B1 vs D1 & \multicolumn{3}{|c|}{} \\
\hline C1 vs D1 & \multicolumn{3}{|c|}{} \\
\hline
\end{tabular}

Table-II: Assessment of mean Absolute Kidney Weight (gm) in various Albino Rats groups $(n=40)$

\begin{tabular}{|l|l|c|}
\hline Groups & Management Given & Absolute Weight \\
\hline $\mathrm{A} 1(\mathrm{n}=10)$ & Control & $0.463 \pm 0.037$ \\
\hline $\mathrm{B} 1(\mathrm{n}=10)$ & Doxorubicin & $0.732 \pm 0.069$ \\
\hline $\mathrm{C} 1(\mathrm{n}=10)$ & $\begin{array}{l}\text { Doxorubicin and } \\
\text { Nigella sativa }\end{array}$ & $0.530 \pm 0.056$ \\
\hline $\mathrm{D} 1(\mathrm{n}=10)$ & Nigella sativa & $0.454 \pm 0.042$ \\
\hline Numerical Assessment & P-value \\
\hline \multicolumn{2}{|c|}{ B1 vs A1 } & 0.001 \\
\hline C1 vs A1 & 0.005 \\
\hline D1 vs A1 & 0.617 \\
\hline B1 vs C1 & 0.001 \\
\hline B1 vs D1 & 0.001 \\
\hline C1vs D1 & 0.003 \\
\hline
\end{tabular}

\section{Absolute Kidney Weight}

Group A1: The mean value of (AKW) Group A1 was $0.463 \pm 0.037$ gram (Table-II).

Group-B1: The mean value of (AWK) Group B1 was $0.732 \pm 0.069 \mathrm{gm}$. The (AWK) of Group B1 was considerably raised $(p=0.001)$ in comparison with Group A1 (Table-II).

Group-C1: The mean value of (AWK) in group-C1 was $0.530 \pm 0.056 \mathrm{gm}$. The (AWK) of Group $\mathrm{C} 1$ was considerably raised $(\mathrm{p}=0.005)$ when compared with Group A1. The (AWK) of Group C1 was considerably reduced $(p=0.001)(A W K)$ when compared with Group B1 (Table-II).

Group-D1: The mean value of (AWK) in group-D1 was $0.454 \pm 0.042 \mathrm{gm}$. The (AWK) of Group D1 was considerably reduced $(\mathrm{p}=0.001)$ when compared with Group B1. The (AWK) of Group D1 was considerably reduced $(p=0.003)$ when compared with Group C1 and Group A1 (Table-II).

Table-III: Comparison of mean Relative Weight $(\mathrm{gm} / 100 \mathrm{gm})$ of kidneys in various Albino Rat groups $(n=40)$

\begin{tabular}{|c|l|c|}
\hline Groups & Management Given & Relative Weight \\
\hline A1 $(n=10)$ & Control & $209.78 \pm 23.16$ \\
\hline B1 $(n=10)$ & Doxorubicin & $481.30 \pm 47.44$ \\
\hline C1 $(n=10)$ & $\begin{array}{l}\text { Doxorubicin and } \\
\text { Nigella sativa }\end{array}$ & $262.59 \pm 26.35$ \\
\hline D1 $(n=10)$ & Nigella sativa & $207.71 \pm 23.17$ \\
\hline Numerical Assessment & P-value \\
\hline B1 vs A1 & 0.001 \\
\hline C1 vs A1 & 0.001 \\
\hline D1 vs A1 & 0.843 \\
\hline B1 vs C1 & 0.001 \\
\hline B1 vs D1 & 0.001 \\
\hline C1 vs D1 & 0.001 \\
\hline
\end{tabular}

\section{Relative Weight of Kidney}

Group A1: The mean value of (RWK) in Group A1, was 209.78 $\pm 23.16 \mathrm{gm} / 100 \mathrm{gm}$ (Table-III).

Group-B1: The mean value of (RWK) in Group B1 was $481.30 \pm 47.44 \mathrm{gm} / 100 \mathrm{gm}$. The (RWK) of Group B1 was considerably raised $(\mathrm{p}=0.001)$ as compared to (RWK) Group A1 (Table-III).

Group C1: The mean value of (RWK) in group-C1 was $262.59 \pm 26.35 \mathrm{gm} / 100 \mathrm{gm}$. The (RWK) of Group C1 was considerably increased $(p=0.001)$ when compared with Group A1. The (RWK) of Group C1 was considerably decreased $(p=0.001)$ when 
compared with Group B1 (Table-III).

Group D1: The mean value of (RWK) in Group D1 was $207.71 \pm 23.17 \mathrm{gm} / 100 \mathrm{gm}$. There was a significant increase $(p=0.843)$ ( $R W K)$ in Group D1when compared with Group A1. A substantial reduction was observed $(p=0.001)(R W K)$ in Group D1when compared with Group B1. A significant decrease was observed $(p=0.001)$ (RWK) in Group D1 as compared to (RWK) Group C1 (Table-III).

\section{Discussion}

DOX has a strong antineoplastic effect against different solid tumors but due to side effects such as nephrotoxicity, its usage is restricted. ${ }^{12}$ Several studies have been accomplished to describe in what way DOX persuaded toxicity. ${ }^{13}$ Because of over-production of ROS anticancer drugs leave their adverse effect. NS seed can up-regulate antioxidant mechanisms due to anticancer drug cyclophosphamide because radiation therapy activates ROS production resulting in damage to normal tissue. NS seed extracts give protection to normal tissues during radiotherapy. ${ }^{14}$

In the present study, the animals of group-B appeared weak and sluggish inactivity and lost their body weight. This decrease in appetite and loss in body weight can be explained on the basis of Doxorubicin-induced nephrotoxicity. Our results are in agreement with other studies, ${ }^{15,16}$ who reported decreased body weight of albino rats after the use of Doxorubicin $1 \mathrm{mg} / \mathrm{kg}$ and 7.5 $\mathrm{mg} / \mathrm{kg}$ body weight, in rats in 3 doses/week respectively. Our results are also in agreement with the observations of a study ${ }^{17}$ who reported that the loss of body weight is due to decreased appetite, after administration of Doxorubicin $10 \mathrm{mg} / \mathrm{kg}$ body weight, repeated on day 10 . The results of a previous study ${ }^{18}$ support our study. They reported that loss of body weights of albino rats are attributed to cytotoxic effects of Doxorubicin i.e. myelosuppression, anemia, and loss of appetite. Our study is supported by a study ${ }^{19}$ who attributed the reduced body weight due to inhibition of protein synthesis, after use of Doxorubicin $2.5 \mathrm{mg} / \mathrm{kg}$ body weight ip, 6 equal doses in 2 weeks. An obvious weight gain was observed in NS pre-treated rats, which proves the ameliorative effect of NS against the renal tissue toxicity of DOX. In our experimental study, DOXinduced rats show a substantial rise in absolute kidney weight due to mild interstitial edema and congestion of blood vessels in the kidneys. Our observations are in conformity with a study ${ }^{17}$ that observed an increase of kidney weight in albino rats treated with Doxorubicin; and a study ${ }^{20}$ investigated that nephrotoxicity due to Doxorubicin results in increased capillary permeability and glomerular atrophy $(8 \mathrm{mg} / \mathrm{kg}$ body weight ip, for 2 days). In our study, the relative kidney weight showed a remarkable increase in Group B when compared with A1, C1, and D1 Groups. This increase in the relative weight of the kidney may be attributed to an increase in the total weight of the kidney and a reduction in Group B1 body weight, so a rise in kidney body weight ratio. Our results are in agreement with studies, ${ }^{21,22}$ who stated that a dose of Doxorubicin $(15 \mathrm{mg} / \mathrm{kg}$ i.p.) remarkably raises the percentage of kidney weight to body weight in rats. The fewer deviations in body weight and kidney weight of Group $\mathrm{C} 1$ show the anti-oxidant property of NS. Increased weight gain has also been observed in a study by a study ${ }^{23}$ who used Nigella sativa as a protector in Alloxan persuaded diabetic rats at a dose of $5 \%$ and $10 \%$ (two groups). In the study, the absolute weight of kidneys in the group C1was decreased. This decrease in weight loss may be endorsed to the improving effects of Nigella sativa. Our results are in agreement with a study ${ }^{24}$ that discovered a decrease in the kidney weight of diabetic albino rats who were given Nigella sativa $100 \mathrm{mg} / \mathrm{kg}$ body weight orally every day for 5 months. In this study, the relative kidney weight of Group C1 was corresponding to Group A1, which may be ascribed to the augmented effects of Nigella sativa, results are in conformity with a study ${ }^{25}$ who observed improvement in kidney weight to total body weight ratio in albino rats after the administration of (Nigella sativa) with Methotrexate. In our study, the animals of group-D1 showed a sustained increase in their body weight throughout the study when compared to group-A1. It explains the Nigella sativa tonic effects on the rat's metabolic activity. Our observations are supported by a study ${ }^{26}$ that observed improved health status and an increase in body weight of albino rats, after the use of Nigella sativa. There was a comparable decrease in the relative kidney weight of Group D1 against the $\mathrm{A} 1, \mathrm{~B} 1$, and $\mathrm{C} 1$ Groups. Our observation is supported by a study ${ }^{25}$ that TQ treatment improves kidney weight with bodyweight ratio in comparison with control. 


\section{Conclusion}

Nigella sativa has a significant therapeutic effect when administered with Doxorubicin against reductions in body and kidney weight.

Authors Contribution: WA: Conception of work and Drafting. SS: Design of work and revising. MM: Interpretation of data and revising. SF: Analysis of data and drafting. AK: Acquisition and analysis of data and revising. AJ: Conception of work and drafting.

All authors critically revised and approve its final version.

Conflict of Interest: Author has declared no conflict of interest.

Sources of Funding: The source of funding was self.

\section{Declaration: None}

\section{References}

1. Sura Salman Ejam. Doxorubicin Induced Nephrotoxicity: Protective Effect of Rosemary leaves. Journal of Babylon University/Pure and Applied Sciences, 2016; 24:234-332.

2. Kamila M Ibrahim, Eman M M, Mona ME, Hend S, Abdel Gawad, Nuha M K et al. Protection from doxorubicininduced nephrotoxicity by clindamycin: novel antioxidant, anti-inflammatory, and anti-apoptotic roles. NaunynSchmiedeberg's Arch Pharmacol; 2020: 393: 739-748.

3. Omar W M, Raslan Y A, Ahmed A E A, Raafat M E, Georgy $S$ G. The Ameliorative Effect of Ellagic Acid and Rosemarinic Acid against Cardio-nephrotoxicity Induced by Doxorubicin in Rats. Inter J of Sci and Research Pub 2016; 6(2): 249-256.

4. Hassanen MR, Mahfouz MK, Farid AS, Fadlullah AH. Biochemical effects of spirulinaplatensis against oxidative stress caused by Doxorubicin Benha Veterinary Med J 2015; 28(2): 147-154.

5. Tacar O, Sriamonsak P, Dass CR. Doxorubicin: an update anticancer molecular action, toxicity, and novel drug delivery system. JPP 2012; 65: 157-170.

6. Khalid Al-Syaad, Essam H. Ibrahim. The Protective Effects of the Aqueous Extract of Saliva Against Biochemical and Histopathological Changes in Kidney and Liver of Male Rats Treated with the Anticancer Drug Doxorubicin. RJPBCS, 2014; 5(6): 237-245.

7. Desai S D, Shaik Hussain Saheb, Kusal K Das, Haseena S. Phytochemical Analysis of Nigella sativa and its Antidiabetic Effect, J Pharm. Sci \& Res, 2015; 7(8): 527532.

8. Elkhateeb A, El-Khishin I, Megahed O, Mazen F. Effect of Nigella sativa Linn oil on tramadol induced hepatic and nephrotoxicity in adult male albino rats. Toxicol Rep 2015; $2: 512-519$

9. Ali Khames, Marwa M. khalaf, Amany M. Gad, Ola M. Abd El-Raouf. Ameliorative effects of sildenafil and/or febuxostat on doxorubicin-induced nephrotoxicity in rats. European Journal of Pharmacology 2017: 805: 118-124.

10. Taseer Ahmed Khan, Muhammad Noman Khan, Ruqaiya Hasan, Habib Fatima, EinasKousar. Effects of Nigella sativa (Black Seed) on Serum Levels of Urea and Uric Acid in Acetaminophen Induced Hepatotoxicity of Commercial
Layer Chickens. J. World's Poult. Res. 2013; 3(4): 89-92

11. Sulmaz Janfaza, Elenaz Janfaza. The study of pharmacologic and medicinal valuation of thymoquinone of oil of Nigella sativa in the treatment of diseases Annals of Biological Research, 2013;3 (4): 1953-1957

12. Meherzia Mokni, Sonia Hamlaoui, SafwenKadri, FeridLimam, Mohamed Amri, Lamjed Marzouki et al. Grape seed and skin extract protects the kidney from doxorubicin-induced oxidative injury. Pak J Pharm Sci May 2016; 29(3): 961-968.

13. Nilesh Shinde, Amit Jagtap, Vaishali Undale, Sujit Kakade, SachinKotwal, Ravindra Patil. Protective effect of Lepidium sativum against doxorubicin-induced nephrotoxicity in rats. RJPBCS 2016; 1(3): 42-49

14. Pereira RV, Kumar A, Pandey BN, Mishra KP, Jagtap AG. Radioprotection by Macerated Extract of Nigella sativa in Normal Tissues of Fibrosarcoma Bearing Mice. Indian J Pharm Sci 2012; 74 (5): 403-414

15. Zeba farooqi, Faizan Ahmed, Sana Rizwan, Faaiza Shahid, Aijaz Ahmed, Farah Khan. Protective effect of Nigella sativa oil on cisplatin-induced nephrotoxicity and oxidative damage in rat kidney. Biomedicine \& Pharmacotherapy 2017: 85: 7-15

16. Pratibha Kamble, Sameer Kulkarni, Matadeen Mishra, Dayanand A. Bhiwgade. Cholesterol, Biomarkers and Cancer Therapy, world Journal Of Pharmaceutical Research, 2015; 4(5): 1181-1189

17. Sudhanshu Jambhulkar, Swathi Deshireddy, Dinesh BabuJestadi, Latha Periyasamy. Quercetin Attenuating Doxorubicin Induced Hepatic, Cardiac and Renal Toxicity in Male Albino Wistar Rats. AJPCT 2014; 2(8): 985-1004

18. Al-Hassawi WW, Al-Sammak MA. Effect of doxorubicin on the histological structure of the kidneys in male albino rats. J Fac med Baghdad 2013; 55(4): 384-389.

19. Marco Cascella, Giuseppe Palma, Antonio Barbieri, Sabrina Bimont, Nagoth Joseph Amruthraj, Maria Rosaria Muzio et al. Role of Nigella sativa and Its Constituent Thymoquinone on Chemotherapy-Induced Nephrotoxicity: Evidence from Experimental Animal Studies. Nutrients 2017: 9: 625.

20. Sara Hosseinian, Mousa-Al-Reza Hadjzadeh, Noma Mohamadian Roshan, Majid Khazaei, Samira Shahraki, Reza Mohebbati et al. Renoprotective Effect of Nigella sativa against Cisplatin-induced Nephrotoxicity and Oxidative Stress in Rat. Saudi J Kidney Dis Transpl 2018;29(1): 19-29.

21. Ahmed m kokab, Mahmuod Abd-elkareem Nasser Khalil, Alaa el Din H Syed. Protective effect of Nigella sativa on 4nonylphenol-induced nephrotoxicity in Clarias gariepinus. Science of the Total Environment 2018: 5; 692-699.

22. Manish S, Pankaj P, Swaraj P, Koti BC, Swamy AHMV. Cardioprotective effects of 'Qolest' a polyherbal formulation against doxorubicin-induced cardiotoxicity in Wistar rats. IJRPS 2011; 1(3): 85-100.

23. Ibrahiem TTA. Beneficial effects of diet supplementation with Nigella sativa (Black seed) and sesame seeds in alloxan diabetic rats. Int J Curr Microbiol App Sci 2016; 5(1): 411-423.

24. Mahood AKS. Histological study of the effect of Nigella Sativa on diabetic nephropathy in rats. Tikrit Med J 2012; 18(2): 154168.

25. El Sheikh AAK, Morsy MA, Abdalla AM, Hamouda AH, Alhaider IA. Mechanisms of thymoquinone hepatorenal protection in methotrexate-induced toxicity in rats. Mediate Inflame 2015; 7: 12

26. Dollah, M. A., Parhizkar, S., Izwan, M. Effect of Nigella sativa on the kidney function in rats. Avicenna Journal of Phytomedicine 2013;3(2): 152-158 